\title{
Health Literacy: Addressing Well-Being: A Review
}

\author{
FAISAL NOOR AHMAD*1 (D, RAVISHANKAR TL² ${ }^{2}$ AMIT TIRTH³ ${ }^{3}$ PARMIEKA RAWAT ${ }^{1}$
}

Literacy forms an important input in overall development of individual enabling them to comprehend their social, political and cultural environment better and respond to it. Health literacy requires knowledge of health topics. People with limited health literacy often lack knowledge or have misinformation about the body as well as the nature and causes of disease. Without this knowledge, they may not understand the relationship between lifestyle factors such as diet and exercise and various health outcomes. Health literacy plays a key role on the overall health and wellbeing and is now recognized as a determinant of health and has been made a priority of public health agendas, as there is existence of clear scientific evidence regarding its association with health outcomes such as use of health care services, hospitalizations, mortality rates, and adherence to treatment regimens. Therefore, responsive health system that eliminates barriers to clear communication and provides usable and actionable health information and services is important to uplift the current situation.

KEYWORDS: Health, Health Literacy, Oral Health, Programs

\section{INTRODUCTION}

Among the world's adult population nearly $17 \%$ is still illiterate with an estimation of 122 million youth globally, of which young women represent 6o.7\%. ${ }^{1}$ Of all the illiterate adults in the world, $37 \%$ are Indians which makes up to 287 million. The scale of illiteracy among youth represents an enormous challenge. ${ }^{2}$ Beyond the obvious difficulties faced by an illiterate person in modern times, such as few employment opportunities and the inability to effectively communicate, it impacts our society in very profound ways. $^{2}$

Literacy is fully crucial for the development of social and human verse in its ability to transform lives. For civilizations alike, it is a tool to empower and improve one's health, revenue \& relationship with the world. ${ }^{3}$ It forms a key input in complete development of individual which enables them to grasp their social, political and cultural environment better and respond accordingly. Literacy and Education levels are basic pointers for the level of development achieved by a civilization. Extent of Literacy is generally allied with important personae of recent civilization such as modernization, urbanization, industrialization, communication and e- commerce. The sharing of ideas, perspectives and concerns also leads to greater levels of mutual understandings and caring and ultimately strong community spirit. ${ }^{4}$

At the national level, in a participative democracy like India, a literate population is required to build a nation with strong social, economic and political foundations. The Effectiveness in literacy abilities open the access to more educational \& employment opportunities that aids the people to pull themselves out of poverty and lingering underemployment. As a community's education level and social awareness increase, the population becomes "activated" and is more likely to initiate health-related interventions. This raised consciousness can lead to higher participation rates in vaccination programs, and more active involvement in community hygiene and sanitation interventions, altogether can lead to a decline in the frequency and incidence of various infectious diseases. ${ }^{4}$

The ability to obtain process and understand health evidence desirable to make conversant health decisions is known as health literacy. The process of gaining health information, assessing its concept and applying health prevention \& treatment plans appropriately requires new skill development. It is interaction between culture \& society, the health system, education system, language and oral health outcomes indicating that it could be a new element of oral health and should be measured more intensively in oral health research. ${ }^{5}$

The intricacy of the healthcare system provided, it is not astounding that limited health literacy is associated with unfortunate health. According to research studies, individuals with limited and low literacy skills are more likely to skip the more 
important preventive measures, for example: the screening tests, visiting the healthcare system when they are sick and are more likely to have chronic conditions and are less able to manage them effectively rather they make greater use of facilities designed to treat impediments of disease \& fewer use of services designed to prevent the complications. ${ }^{4}$

The pitch of the health literacy is growing briskly, expanding to involve a larger and more interdisciplinary addressee, \& with that there occur a superior recognition of its complex and multi-layered nature. One such field is the Oral Health. ${ }^{6}$

Oral health is the key necessity to general health and well-being at every juncture of life. A fine fettle mouth empowers not only nutrition of the human body, but also augments social interaction which promotes selfesteem \& the feeling of well-being. To uphold oral health \& diseases when they occur, one should be able to comprehend, construe, and act on oral health data, whether it is communicated verbally or in written form. Hence, the importance of health literacy should be attained by every individual to maintain basic oral health. ${ }^{5}$

This review article enlightens on the significance of health literacy with its connotation with oral health, its contribution towards different disciplines and in assessment of health literacy.

\section{IMPORTANCE OF HEALTH LITERACY}

- Crucial for successful and fruitful access to care and use of amenities, self-care of continuing conditions, and maintenance of health \& eudemonia by active life. - The Ultimate of healthcare is that it requires individuals to have a more active role in pronouncements, decisions and management. ${ }^{7}$

\section{WHAT CAN BE DONE TO EXPAND AND FURNISH THE LOW HEALTH LITERACY?}

The Improvement of the health literacy is the accountability of health organizations, healthcare systems, and healthcare professionals worldwide. It is perilous for the patients to develop health literacy so that they can be more proactive in their health regimes. When patients engagement increase, they are able to make more well-versed decisions which increases the patient gratification, adherence, and can ultimately improve the overall outcome. ${ }^{8}$

\section{FACTORS AFFECTING HEALTH LITERACY}

- Illiteracy

- Poverty

- Inequality, discernment and traditional culture beliefs

- Deep distrust of the prevailing medical system

- Special challenges: Scheduled Tribes, rural villages and slums. ${ }^{9}$

\section{SIGNIFICANCE OF ORAL HEALTH LITERACY}

OHL (Oral Health Literacy) is the new imperative for better oral health as health literacy is now considered a determinant of health. Oral health is an essential part to overall health and well-being of an Individual. With underprivileged, poorer and untreated oral health and conditions, the impact on quality of life (QoL) will be deleterious.

According to oral health framework, Oral Health Literacy (OHL) can be considered as the aids necessary for society to comprehend the causes of poor oral health; to learn \& implement fundamental aspects of positive oral self-care behaviors; to interconnect with oral health care providers. Also, research has revealed that OHL is allied with increased prevalence of OHRQoL impacts lower level oral health literacy directly affected the oral health status. Refining health literacy is a critical goal in refining health outcomes. Healthcare providers can make an optimistic approach on improving health outcomes by assessing practice \& working to advance communication and knowledge. The improvement in oral health literacy will require intensive collaborative efforts and collective approaches among healthcare providers. ${ }^{10}$

Basic awareness of oral health issues for many Indians may be quite limited because of cultural or language barriers or problems with literacy. Among Indians, many lack understanding and cognizance of the importance of oral health and its essential relationship with their overall health. ${ }^{11}$ According to the report, the literacy blockade to the health has been made largely unseen until recently because it was not often recognized and poorly understood and many health care providers could not address the literacy needs of their patients. ${ }^{12}$ Deficiency of access to care results in patient's perceived need for care, lack of oral health literacy, geographic distribution of dentists and dental teams, economical drawback, individuals with physical disabilities and/or challenges. ${ }^{13}$ 
It is important that the government, dental professionals, and IDA work together to break the blockades to access the oral health. They have been identifying and addressing access issues by their various initiatives -- which provide a stage to forge a mutual ground in order to yoke opportunities and create viable solutions which provide improved oral health through prevention \& treatment for vulnerable populations. ${ }^{14}$

\section{HEALTH LITERACY FRAMEWORK}

It is the process of gaining health information, appraising the concepts \& applying health prevention and treatment plans correctly with requirement of the new skill development. Health literacy is forms a relationship between culture and society, the health system, education system, language and its outcomes. ${ }^{15}$

Dentistry has made improvements in terms of determining the scope of low health literacy and who is affected by it; understanding the economical and health-related burdens placed on health care providers and patients; and defining in what way to attain health literacy on an individual and on the community basis. ${ }^{12}$

A committee formed by the Institution of Medicine in the U.S. to comprehend health literacy \& its influence on health outcomes have developed a health literacy framework. This framework identifies three major areas that may play key roles in influencing individual's health literacy: culture and society, health and the education system. Interventions should be directed towards these three areas to improve health literacy. ${ }^{16}$

\section{DIMENSIONS OF ORAL HEALTH LITERACY}

According to Sorensen et. al (2012) $)^{17}$ the 5 important key extents for health literacy are as follows-

1. Health care system acquaintance and utilization;

2. Elementary health knowledge;

3. Marketing and the consumer behavior;

4. Health capabilities at the workplace;

5. Political participation. ${ }^{17}$

\section{HEALTH LITERACY LEVELS}

There are three distinct levels in health literacy, which are:

1. Functional: basic skills in reading and writing necessary for effective functioning in a health context.
2. Interactive: more advanced cognitive literacy and social skills that enable vigorous contribution in health care.

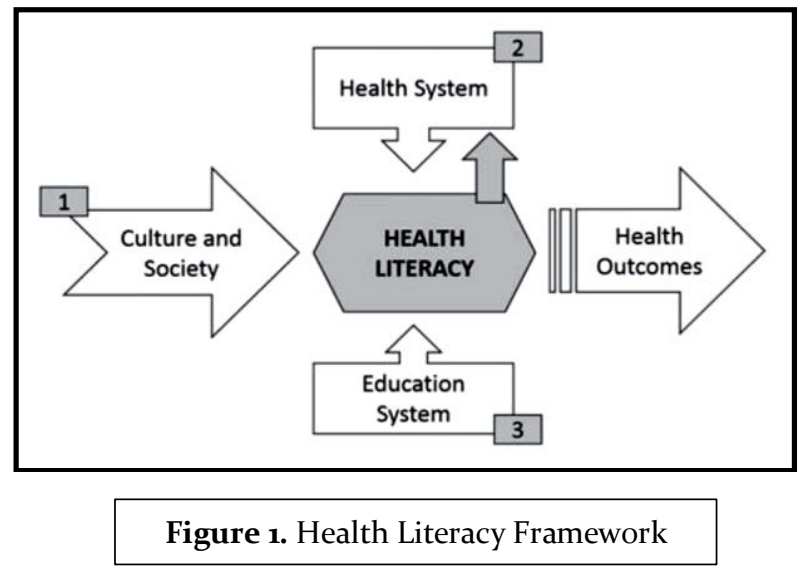

3. Critical: it is the capability to critically analyze and use data to participate in actions that overcome structural blockades to health. ${ }^{18}$

\section{ASSOCIATION AMONG ORAL HEALTH \& HEALTH CONSEQUENCES}

In recent years, an increasing number of studies have been dedicated toward the study of health literacy. The health literacy construct can be understood as the capacity of people to attain and process the elementary health information and services needed to make appropriate health policies and decisions. Researchers have built up a causal pathway linking OHL to oral health outcomes. It is believed that low health literacy directly relates to less knowledge about oral health, which leads to a decreased adherence to positive oral health behaviors. Moreover, enlarged health literacy ideas and knowledge is associated with better patientdentist communiqué, which can contribute to lower dental anxiety and thus an increased likelihood of seeking dental treatment.

The social and economic circumstances of individuals influence their behavioral choices, and consequently affect their health outcomes. Yet, to act on the grounds of diseases, it is important to focus on health promotion with appropriate strategies. ${ }^{19}$

Despite all the communication resources existing today, especially with the dawn of the Internet, many persons still do not use these resources and do not have access to health information. This result brings 


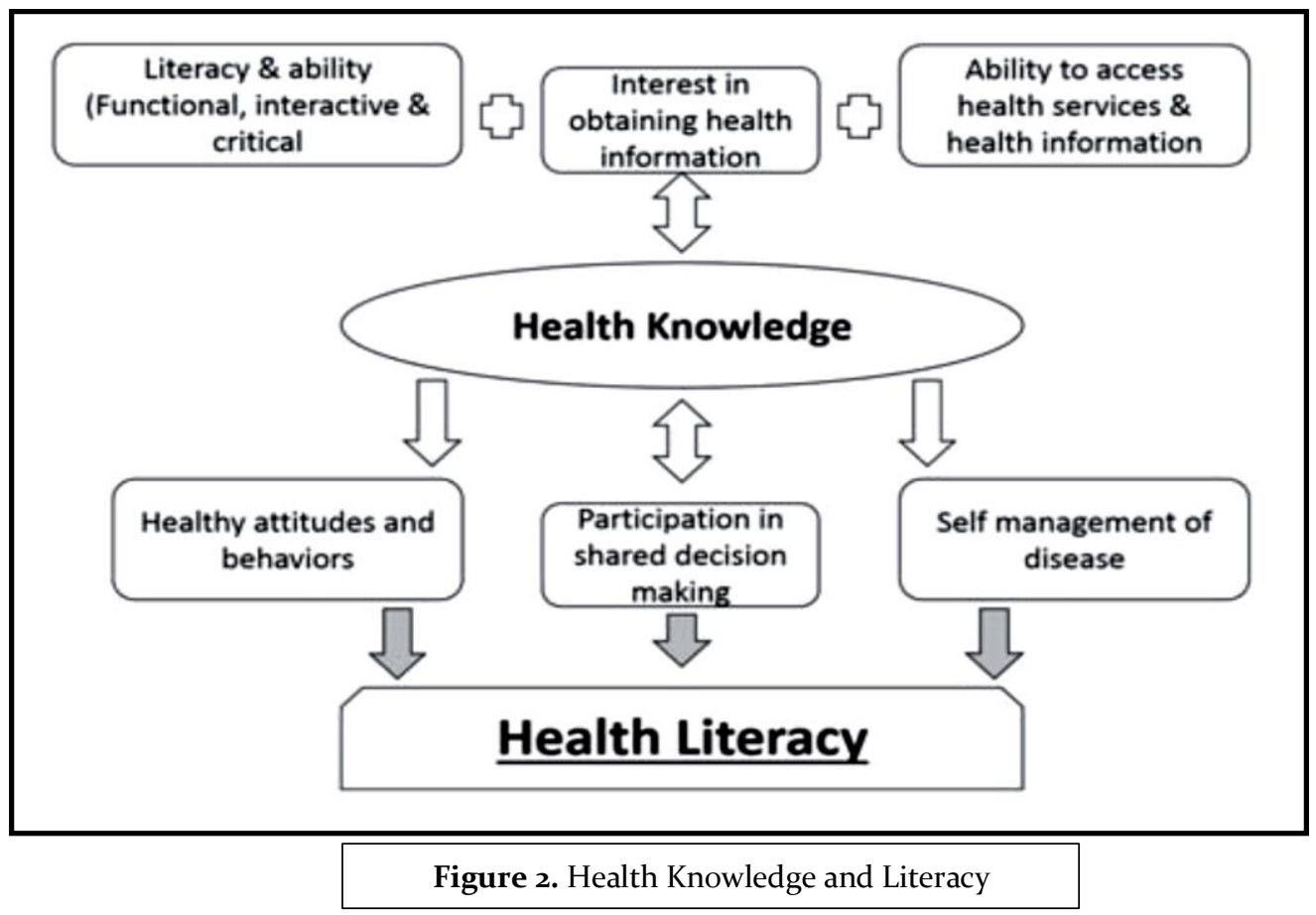

with it the issue of where the loopholes between the numerous bits of health information in the media exist and how one can accesses these bits of intel. Health literacy has been shown to be an intermediary among health determinants, for instance, income, education, race, health behavior and health outcomes. ${ }^{20}$

Health literacy is one of the strategies of health promotion according to Nutbeam. ${ }^{21}$ The increasing health literacy potential in promoting the better decisions based on information, reduce health hazards, increase prevention and well-being and increase transit through health schemes, patient care and quality of life. ${ }^{21}$

\section{HEALTH LITERACY AND PUBLIC HEALTH}

At the level of an individual, ineffective communication due to underprivileged health literacy will result in errors, deprived quality, and risks to patient safety of the healthcare services.

At a population level, health literate individuals are able to partake in the ongoing public and private dialogues about health, medicine, scientific knowledge and cultural principles. Thus, the doles of health literacy effect the full range of life's activitieshome, work, society and culture. In the population, it may also lead to more equity and sustainability of changes in public health. ${ }^{22}$

\section{TOOLKIT \& ASSESSESSING THE ORAL HEALTH LITERACY}

The purpose of this tool kit includes the apprise and to provide resources on oral health literacy to dental and healthcare professionals and other individuals and programs providing care and services to individuals at risk for dental diseases. The knowledge hence, enlarged from understanding oral health problems and how effectively to reach individuals with low oral health literacy will aid in providing optimal dental care, support and education.

Perceiving patients with low reading ability for various signs allows the dentist to offer the assistance a patient need without causing any embarrassment or uneasiness. There has been no availability of medical or dental test that systematically measure a person's reading fluency, terminology, ability with numbers, oral and written communication skills and his or her ability to meet the demands engaged on these abilities by the healthcare system. However, valid and reliable instruments are available to measure key aspects of this literacy skills. ${ }^{23}$

\section{THE THREE A'S FOR ORAL HEALTH INFORMATION:}

Oral health information should be:

- Accurate: By means of health literacy best practices does not mean "dumbing-down" the facts or distorting 
the science. The practices of Health literacy ensure that the information is presented accurately and in ways that people can understand.

- Accessible: An often over-looked aspect of health literacy is the issue of access. Just because anyone can produce oral health information doesn't mean people see it or can use it. The World Wide Web is not always the best way to reach "the general public."

- Actionable: In the health arena, we classically want people to start or stop doing something, or do more or not as much of of something. We often spend our resources giving people background information instead of endorsements. Some background information may be significant, but make sure you provide actionable information so the people you want to target can do something with the info delivered. ${ }^{23}$

\section{HEALTH LITERACY TOOLKIT}

The health literacy assessment tools most commonly used in medical practice includes the following:

1. REALM (Rapid Estimate of Adult Literacy in Medicine) (1991) - Word recognition test. ${ }^{24}$

2. REALM (1993) - Shortened version of REALM. ${ }^{24}$

3. Test of Functional Health Literacy in Adults (1995) Reading comprehension and numerical ability. ${ }^{24}$

4. NVS (Newest Vital Sign) (2005) - Literacy and numeracy skills. ${ }^{24}$

\section{THE USE OF SOCIAL MEDIA}

Through the times, platforms like Facebook, YouTube, Twitter and other social media tools to circulate health messages has grown significantly, and continues to trend upward and speedily. Using social media tools has become an active way to enlarge reach and spread, foster engagements and increase access to reliable, science-based health memoranda. The Assimilating social media into health communication campaigns and activities allows health communicators to influence social dynamics and networks to encourage participation, conversation and community, altogether can help spread key messages and help in the influence of health decision making. ${ }^{25}$

\section{HEALTH LITERACY PROGRAMS WORLDWIDE}

Public Health Agency of Canada (PHAC) ${ }^{26}$ designated health literacy as a priority area of work and had a position for senior advisor in health education and literacy over the previous years. The PHAC was also reported to have custom-made a national thing "tank to advice" on the expansion of a tactic to health literacy within the agency as well as supported the public health association of British Colombia (PHABC) who organized subsequent national think tanks which resultant in the development of a national draft approach to health literacy. ${ }^{26}$

Chinese Association for Health Education (CASE) is aimed to unite health education work nationwide, promote the undertaking of health education and the construction of socialist material and cultural civilization in China and increase the knowledge of health and science among Chinese people in order that they develop healthy behaviors and lifestyles. ${ }^{27}$

\section{HEALTH LITERACY PROGRAMS IN INDIA}

In 1988, the national literacy mission was launched to aim the literacy rate of $75 \%$ by 2007 (National Literacy Mission), the effort through the 1947. Though this was a superior than six-fold improvement, the level is well below the world average literacy rate of $84 \%$ (literacy in India, 2012).

No government policies explicitly focusing on health literacy were reported, however, multiple government reports on health issues such as tobacco use, health equity, and non-communicable disease, state of urban health in Delhi and the practice of information technology for health referred to as the significance of health literacy.

Kalyani is an initiative of Ministry of Health and Family Welfare of the Govt. of India and has been called the longest running public health campaign in the nation. Program is broadcast over Doordarshan and National public television, in states of INDIA, targeting approximately $50 \%$ of INDIA's population. These 9 states experienced poorest health indicators in the Nation. Themes of the television program, reinforced by in community efforts, are Reproductive \& Child Health, Malaria, Tuberculosis, HIV/AIDS, Anti-tobacco, Cancer, Water Borne Disease, Insulindependent diabetes (IDD), Blindness, and Leprosy and Food Safety. ${ }^{28}$

Darpana Academy, based in Ahmedabad, India, uses methods like - Indian dance culture, puppetry, music, theatre, and television to train, empower, and promote awareness about critical issues India is facing today, Health, being one of the primary focus areas for their work (2012). Health issues that Darpana projects are reported to have addressed include family planning; diabetes; cervical cancer; maternal; and infant mortality; HIV/AIDS; children's health; hygiene; 
sanitation; the medical and social impact of HIV/AIDS for at risk population, including truck drivers, sex workers, and their clients and port labor; leprosy; and addictions. $^{29}$

Public Health Foundation of India (PHFI) ${ }^{30}$ is a publicprivate initiative that is reported to have conducted community-based health literacy campaigns to effectively build engagement and facilitate action for improved health outcomes at the grassroots. The organization has conducted health literacy assessment, participatory action research projects on increasing health literacy at the grassroots relating risk factors and symptoms of selected chronic disease prevention opportunities in three states in India. Various campaigns conducted throughout so far have apparently used mass media through community and commercial radio, ads in newspaper, participatory mid-level media using songs, street plays, puppetry shows, public meetings, dance shows, and adapted board games as well as interpersonal communication via board games as well as via peer education via a cascade approach. ${ }^{30}$

Maanavta se Anmol Mann Tak (2010-2012)27: Under the sponsorship of the National Mental Health Program (NMHP), Ministry of Health and Family Welfare. Government of India, the PHFI accomplished the implementation and operation of a pilot awareness generation campaign on mental and psychological health. The initiative was started with the key objective of inspiring timely help-seeking behaviors by individuals and families through partaking information on available services \& efforts in stigma reduction in 10 districts of Andhra Pradesh, Assam, Gujarat, Uttar Pradesh, and Delhi. A series of activities were conducted in partnership with civil society organization with close association with the District Mental Health Program teams. ${ }^{27}$

The Self-Employed Women's Association (SEWA) ${ }^{31}$ It is a trade union including nearly a million selfemployed women in Gujarat, India. The organization works to link health security, which means that all economic activities are SEWA have a healthy component and all health action. The association has jointly organized health insurances to pay for health costs, systematizes child care and held campaigns with state and national level authorities for child care as an entitlement for all women workers. Training of the traditional midwives, so that they become the barefoot doctors of their communities, aids in promoting health and well-being by providing access to health information and health education and accentuate selfreliance for women in economic terms and in rapports of women themselves owing, controlling and managing their own health activities (SEWA, 2009). ${ }^{31}$ Gender Resource Center (GRCs) ${ }^{32}$ are being reported to be implemented in Delhi, India for its overall empowerment of women among the areas of health literacy, legal awareness and skill advancements. The efforts to accomplish greater convergence of programs and activities of government for the women and other agencies through single window information and facilitation centers for the community woman to provide broader acquaintance to available services and better placement opportunities. ${ }^{32}$

\section{CONCLUSION}

Health literacy plays a crucial role on the general health and wellbeing. People with inadequate health literacy often lack knowledge or have misinformation about the body, about the nature and causes of disease. Various factors like proper usage of health care services, communication of health issues with health care providers, leading healthy lifestyle, good hygienic conditions, taking preventive measures like immunization, which could show to impact an individual's physical and mental wellbeing are directly or indirectly related to health literacy. Hence, the suggestion about the promoting health literacy will make a healthy community, and it should be measured as a primary public health objective.

Health literacy is described as the fuel for improving the quality of health \& health care necessities. It's the essential skills that allow an individual to function within the health care environment. It is a health care provider responsibility to make sure that health information and repair provided are easily understandable, accessible, and the other people are ready to grasp and apply these recommendations. ${ }^{29}$

\section{REFERENCES}

1. Statistics | Education | United Nations Educational, Scientific and Cultural Organization." Statistics | Education | United Nations Educational, Scientific and Cultural Organization.

2. The Power of Literacy: Women's Journeys in India, Indonesia, Philippines and Papua New Guinea. 2012, Asia South Pacific Association for Basic and Adult Education (ASPBAE)

3. International Literacy Statistics: A Review of Concepts, Methodology and Current Data-UNESCO Institute for Statistics. 
4. US Department of Health and Human Services. Quick Guide to Health Literacy. (Online Article). Available from: https://health.gov/healthliteracy online/. [Last Accessed on $12^{\text {th }}$ December, 2019]

5. Dental Health Foundation Ireland. Links between Oral and General Health (Online Article). Available from:

https://www.dentalhealth.ie/dentalhealth/causes/gene ral.html [Last Accessed on $12^{\text {th }}$ December, 2019]

6. Berkman ND, Davis TC, McCormack L. Health Literacy: What Is It?, Journal of Health Communication. 2010;15:9-19. https://doi.org/10.1080/10810730.2010.499985

7. Institute of Medicine. Health Literacy: A prescription to end confusion. Nielsen-Bohlman L, Panzer A, Kindig DA, editors. Washington, D.C., National Academy Press 2004.

8. Centers for Disease Control and Prevention. (Online Article). Available from: https://www.cdc.gov/healthliteracy/learn/Understandi ng.html [Last Accessed on $12^{\text {th }}$ December, 2019]

9. Health Education Library for People (HELP). Chapter 13: Health Literacy in India: A Unique Challenge. (Online Article). Available from: (Online Articleo). Available from: https://www.cdc.gov/healthliteracy/learn/unders tanding.html [Last Accessed on $12^{\text {th }}$ December, 2019] 10. Sajjanshetty M, Rao A, Gururaghavendran R, Shenoy R, Mithun Pai B H. Oral health knowledge and practices: their influence on oral health status of auxiliary health workers in health centers of Mangalore, India. J Indian Assoc Public Health Dent 2019;17:97-102.

https://doi.org/10.4103/jiaphd.jiaphd_173_18.

11. Baliga SM. Child oral health-care literacy in India: Can access to services be improved? J Indian Soc Pedo, Prev Dent. 2019; 37:1-2.

12. Institute of Medicine (US) Committee on Health Literacy; Nielsen-Bohlman L, Panzer AM, Kindig DA, editors. Health Literacy: A Prescription to End Confusion. Washington (DC): National Academies Press (US); 2004. 2, What Is Health Literacy? (Online Article) Available from: https://www.ncbi.nlm.nih.gov/books/NBK216035 [Last Accessed on $12^{\text {th }}$ December, 2019 ] 13. Patrick DL, Lee RSY, Nucci M, et al. Reducing Oral Health Disparities: A Focus on Social and Cultural Determinants. BMC Oral Health 2006; 6:S4. https://doi.org/10.1186/1472-6831-6-S1-S4

14. Indian Dental Association (IDA). Advocacy (Online Article). Available from: https://www.ida.org.in/Advocacy/Details/Advocacy. [Last Accessed on: $14^{\text {th }}$ December, 2019]
15. McCray AT. Promoting health literacy. J Am Med Inform Assoc. 2005;12(2):152-163. https://doi.org/10.1197/jamia.M1687.

16. Hongal S, Torwane NA, Goel P, Chandrashekar BR, Jain M, Saxena E. Assessing the oral health literacy: A review. Int $\mathrm{J}$ Med Public Health 2013;3:219-24. https://doi.org/10.4103/2230-8598.123406

17. Sørensen, K, Van den Broucke S, Fullam J, et al. Health literacy and public health: A systematic review and integration of definitions and models. BMC Public Health 2012;12:8o. https://doi.org/10.1186/1471-2458-1280

18. Ishikawa H, Kiuchi T. Health literacy and health communication. Biopsychosoc Med. 2010;4:18. https://doi.org/10.1186/1751-0759-4-18

19. Tran TD, Krausch-Hofmann S, Duyck J, et al. Association between oral health and general health indicators in older adults. Sci Rep. 2018;8:8871. https://doi.org/10.1038/s41598-018-26789-4

20. Nielsen-Bohlman L, Panzer AM, Kindig DA, eds. Health Literacy: A Prescription to End Confusion. Washington, DC: The National Academies Press; 2004:5

21. Nutbeam D. Health literacy as a public health goal: a challenge for contemporary health education and communication strategies into the 21st century. Health Promotion International 2000;15(3):259-67.

22. Van den Broucke S. Health literacy: a critical concept for public health. Arch Public Health. 2014; 72(1):10. https://doi.org/10.1186/2049-3258-72-10

23. Chopra A, Rao NC, Gupta N, Vashisth S. Oral health literacy: An approach to end oral health disparities. SRM J Re Dent Sci 2013; 4:16-20.

24. Centers for Medicare and Medicaid Sercives (CMC). (Online Article).Available From: https://www.cms.gov/Outreach-andEducation/

Outreach/WrittenMaterialsToolkit. [Last Accessed on $13^{\text {th }}$ December, 2019]

25. Centers for Disease Control and Prevention (CDC). The health communicator's social media toolkit. (Online pdf). Available from: http://www.cdc.gov/socialmedia/tools/guidelines/pdf /socialmediatoolkit_bm.pdf. [Last Accessed on $14^{\text {th }}$ December, 2019]

26. Rootman I, Gordon-El-Bihbety D. A vision for a health literate Canada: report of the expert panel on health literacy. CPHA. 2008. (Online Pdf) Available from: http://www.cpha.ca/uploads/portals/h/report e.pdf [Last Accessed on $16^{\text {th }}$ December, 2019]

27. Roundtable on Health Literacy; Board on Population Health and Public Health Practice; Institute of Medicine. Health Literacy: Improving Health, Health Systems, and Health Policy around the 
World: Workshop Summary. Washington (DC): National Academies Press (US); 2013 Jul 10. Appendix A, Health Literacy around the World: Part 1 Health Literacy Efforts Outside of the United States. Available from: https://www.ncbi.nlm.nih.gov/books/NBK Darpana Academy of Performing Arts 202445/ [Last Accessed on $13^{\text {th }}$ December, 2019]

28. Ministry of Health and Family Welfare. Government of India website. Available from: https://mohfw.gov.in/ [Last Accessed on $\mathbf{1 2}^{\text {th }}$ December, 2019]

29. Darpana Academy of Performing Arts (Online Article).

Available https://pubmed.ncbi.nlm.nih.gov/24872976/ [Last Accessed on $14^{\text {th }}$ December, 2019]

30. Healthy India (Online Website). Available from: http://www.healthy-india.org. [Last Accessed on $16^{\text {th }}$ December, 2019]

31. Self Employed Women's Association (SEWA). (Online Website). Available from: http://www.sewa.org/. [Last Accessed on 12 $^{\text {th }}$ December, 2019]

32. Gender Resource Centre (Gujrat). (Online Website). Available from: http://www.grcgujarat.org/ [Last Accessed on 14 ${ }^{\text {th }}$ December, 2019]

Source of support: Nil, Conflict of interest: None declared

Cite this article as:

Ahmad NF, Ravishankar TL, Tirth A, Rawat P. Health Literacy: Addressing Well-Being: A Review. Int Healthc Res J. 2020;4(5):105-112. https://doi.org/10.26440/IHRJ/0405.08355

\section{AUTHOR AFFILIATIONS: ${ }^{*}$ Corresponding Author)}

1. Post Graduate Trainee [ORCID ID: https://orcid.org/oooo-0oo1-5883-3433 (Dr. Faisal Noor Ahmad)]

2. Professor \& Head

3. Professor

Department of Department of Public Health Dentistry, Kothiwal Dental College \& Research Centre, Moradabad, India

Contact corresponding author at: noorfaisalahmad[at]gmail[dot]com 